\title{
Jogos e objetos matemáticos como recurso pedagógico: terapia wittgensteiniana dos conceitos psicológicos
}

Games and mathematical objects as pedagogical resource: wittgensteinian therapy of psychological concepts

\author{
Jaqueline Valerio da Cruz \\ Paulo Vilhena da Silva**
}

\section{Resumo}

Este artigo é um recorte de nossa pesquisa de mestrado, em andamento, a qual tem por intuito apontar reflexões acerca da utilização de conceitos psicológicos atribuídos ao uso de jogos e objetos matemáticos como recurso pedagógico. Algumas pesquisas presentes na literatura da Educação Matemática apontam que a utilização desses recursos favorece a aprendizagem da Matemática por parte dos alunos, desenvolvendo habilidades como 0 raciocínio lógico, memória, concentração, entre outros. Por vezes, esses conceitos psicológicos são tratados como se fossem processos mentais, ou mesmo atribuídos a aspectos físicos, resultado de uma concepção referencialista da linguagem, isto é, algo que é independente da linguagem, o que pode trazer equívocos no planejamento para se trabalhar em sala de aula. Desta forma, basear-nos-emos nas ideias do Filósofo Ludwig Wittgenstein, o qual nos apresenta a terapia filosófica como meio de esclarecer a utilização de nossas expressões linguísticas, realizaremos então uma discussão teórica acerca dos conceitos psicológicos referentes ao uso de jogos e objetos matemáticos, como recurso pedagógico. Nossos resultados parciais apontam que a terapia dos conceitos psicológicos pode nos ajudar a evitar equívocos no que diz respeito a compreensão das habilidades desenvolvidas por meio do uso de jogos e da utilização de objetos manipuláveis nas aulas de matemática.

Palavras-Chave: Jogos. Objetos matemáticos. Terapia Wittgensteiniana. Conceitos Psicológicos. Habilidades Matemáticas.

\section{Abstract}

This article is a excerpt from our ongoing master's research, which aims to point out reflections on the use of psychological concepts attributed to the use of games and mathematical objects as a pedagogical resource. Some researches in the literature of Mathematical Education indicate that the use of these resources favors the learning of Mathematics by the students, developing skills such as logical reasoning, memory, concentration, among others. Sometimes these psychological concepts are treated as if they were mental processes, or even attributed to physical aspects, the result of a

\footnotetext{
* Licenciada em Matemática, é mestranda do Programa de Pós-Graduação em Educação em Ciências e Matemáticas - (IEMCI/UFPA). E-mail: cruzvjaque@gmail.com

** Doutor em Educação Matemática, é professor da Faculdade de Matemática do Instituto de Ciências Exatas e Naturais, da Universidade Federal do Pará (UFPA). E-mail: pvilhena@ufpa.br.
} 
referentialist conception of language, that is, something that is independent of language, which can bring misconceptions in planning to work in classroom. Thus, based on the ideas of the philosopher Ludwig Wittgenstein, who presents us with philosophical therapy as a way of clarifying the use of our linguistic expressions, we will then conduct a theoretical discussion about the psychological concepts related to the use of games and mathematical objects. as a pedagogical resource. Our partial results indicate that the therapy of psychological concepts can help us avoid misunderstandings regarding the understanding of the skills developed through the use of games and the use of manipulable objects in math classes.

Keywords: Games. Mathematical objects. Wittgensteinian therapy. Psychological Concepts. Mathematical skills.

\section{Introdução}

No que diz respeito à Educação, uma das principais discussões é a dificuldade encontrada nos alunos em aprender conteúdos referentes à matemática, sendo assim, diversas vertentes do campo da Educação matemática vêm se dedicando a buscar meios para solucionar ou amenizar este problema. Vários recursos, didáticos e metodológicos, têm sido apontados como meios de facilitar o aprendizado dos alunos. E a utilização de objetos e de jogos matemáticos, nas últimas décadas, tem ganhado cada vez mais força e receptividade nos ambientes escolares, seja pela ludicidade e motivação para os alunos, como pela oportunidade de se trabalhar temas acerca da Matemática de uma maneira mais atrativa. Inúmeros benefícios são atribuídos à prática dos jogos e materiais manipuláveis, como por exemplo, o desenvolvimento do raciocínio lógico e da memória (CABRAL, 2006). Por outro lado, quando passamos a analisar tais conceitos utilizados em pesquisas da Educação Matemática, percebemos que ainda estão fortemente influenciadas pelas ideias platônicas, cartesianas, etc. (SILVA; SANTOS; GOULART, 2018; FERREIRA; IGLIORI, 2014; MORO, 2009).

A busca por um fundamento último para explicar conceitos ainda é muito evidente. Alguns dos questionamentos que salientam esta problemática na Educação matemática são: "como o processo de aprendizagem funciona?”; "o que podemos fazer para melhorar a compreensão destes alunos?"; "o que devo fazer para que meu aluno raciocine corretamente?"; "o que fazer para que meu aluno 
'decore' (memorize) as regras?"; dentre outras. Tais questionamentos, por vezes, nos levam a procurar explicações únicas, como se existisse apenas um mecanismo de ensino, uma única maneira, uma receita pronta, uma referência a algo físico, a "objeto", "concreto", algo representativo na realidade, que pudesse melhorar o aprendizado dos alunos, atitude resultante da adoção de uma concepção referencialista da linguagem.

Isso se dá pelo fato de tais teorias educacionais - baseadas em ideias empiristas, metafisicas, mentalistas, construtivistas - apontarem a aquisição do conhecimento como algo desatrelado à linguagem, em que os significados de cada processo evolutivo do ser humano está diretamente conectado à um aspecto psicofísico (DONAT, 2012). Essa necessidade de apontar algo para esclarecer os fatos do mundo, de acordo com a perspectiva Wittgensteiniana, é uma concepção reducionista da linguagem, pois acaba tornando-a apenas descritiva, com intuito de comunicar os fatos do mundo. Não estamos aqui negando que existam processos físicos (cérebro), no aprendizado, mas sim que a forte concepção referencialista da linguagem, como apresentado por Gottschalk (2015), acaba por trazer certos equívocos no modo de planejar a utilização desses recursos educativos.

Para o Filósofo Austríaco Ludwig Wittgenstein, quando nos deparamos com dificuldades e confusões conceituais, podemos alcançar os esclarecimentos de forma terapêutica, seguindo um método de observação reflexiva, que ele veio a chamar de "terapia filosófica", o filósofo propõe uma "cura" para os equívocos que são oriundos do uso dogmático da concepção referencial da linguagem.

Dessa forma, devemos buscar mudar nosso modo de conceber as coisas do mundo e reconhecer que há outras maneiras de vê-las, como por exemplo, a multiplicidade de aplicações atribuídas ao mesmo conceito ou palavra. É importante que queiramos ver de outro modo, sendo assim, devemos nos livrar dos dogmatismos e em relação ao nosso modo de ver habitual, para tal, seria necessária uma análise gramatical do uso das palavras nos jogos em que estão inseridas, deste modo poderíamos evitar tais confusões. 
Diante disto, nos deparamos com o seguinte questionamento: de que maneira a terapia dos conceitos psicológicos poderia melhorar a compreensão acerca da utilização de jogos e objetos matemáticos, como recurso pedagógico, no que diz respeito ao desenvolvimento de habilidades importantes para um bom desempenho no aprendizado matemático? O que nos leva ao objetivo deste trabalho, que é reflexão acerca da utilização de conceitos psicológicos atribuídos ao uso de jogos como recurso pedagógico, pois ao analisarmos tais conceitos de maneira terapêutica, podemos evitar cometer equívocos e confusões ao planejarmos a utilização de recursos pedagógicos, como o uso de jogos, no âmbito escolar.

\section{A Concepção referencial da linguagem e a Terapia filosófica Wittgensteiniana}

Se os adultos nomeassem algum objeto e, ao fazê-lo, se voltassem para ele, eu percebia isto e aprendia que o objeto fora designado pelos sons que eles pronunciavam, pois eles queriam indicá-lo. Mas deduzi isso dos seus gestos, a linguagem natural de todos os povos, e da linguagem que, por meio da mímica e dos jogos com os olhos por meio dos movimentos dos membros e do som da voz, indica as sensações da alma, quando desejo algo, ou se detém, ou recusa, ou foge. Assim, aprendi pouco a pouco a compreender quais coisas eram designadas pelas palavras que eu ouvia pronunciar repetidamente nos seus lugares determinados em frases diferentes. E quando habituara minha boca a esses signos, dava expressão aos meus desejos (AGOSTINHO apud WITTGENSTEIN, 1975, § 1).

$\mathrm{Na}$ citação acima, temos uma passagem das Confissões 1/8, de Santo Agostinho, a partir da qual Wittgenstein inicia a sua crítica ao uso referencialista da linguagem. Nessa passagem, podemos ver que para Santo Agostinho, as palavras denominam objetos, ou seja, entre palavra e objetos existiria uma relação isomórfica. Segundo esta concepção, ao dizermos algo seria o mesmo que descrevermos alguma coisa, seria uma relação biunívoca, um para um, ou seja, que haveria uma relação entre os elementos que compõem uma proposição e o fatos ou objeto ao qual a proposição está descrevendo, mesma concepção presente no Tractatus (1968), obra de juventude do filósofo austríaco. Nesse livro, as proposições apenas teriam sentido se descrevessem algo no mundo, do 
contrário, esta seria uma proposição falsa. Sendo assim, para determinar as estruturas da linguagem e por consequência do mundo, tais proposições deveriam ser submetidas a uma análise lógica, para decidir se elas seriam verdadeiras ou falsas, e se fossem consideradas falsas não seria de fato, uma proposição (SILVA; SILVEIRA, 2013).

Nas Investigações filosóficas, sua segunda obra, Wittgenstein questionou justamente sua obra anterior, o Tractatus, segundo ele, havia "erros" e precisou rever sua maneira de pensar, reconheceu tais erros como graves, pois segundo ele a estrutura lógica não é a essência da linguagem, mas sim a forma como a linguagem funciona, e a questão primordial é a compreensão do uso de tal linguagem, ou melhor, o significado da linguagem está na forma como à utilizamos nos diversos meios, e contextos como salienta Wittgenstein: "o falar da linguagem é uma parte de uma atividade ou de uma forma de vida" (WITTGENSTEIN,1975, §23).

Mesmo em meio a oposição entre as suas duas filosofias - o "primeiro" e o "segundo" Wittgenstein ${ }^{1}$-, ele continuou seguindo o mesmo ponto de vista, no qual ele afirmava que de fato não há grandes problemas filosóficos e sim que existe uma má compreensão da linguagem, e o que diferencia tais pontos de vistas dentro de suas duas obras é a forma como é vista a linguagem em relação ao mundo (SILVEIRA; TEIXEIRA JUNIOR; SILVA, 2018). De acordo com as ideias de Wittgesntein (1975), a filosofia da linguagem vem a ser muito mais que apenas referencialista. Como apontado por Hebeche:

Consciência é linguagem. Ou melhor: só na linguagem é que se pode tratar do mundo da consciência. O significado das palavras "mundo" e "consciência" é o modo como elas são usadas na linguagem. Trata-se de eliminar a ideia de que a complexidade dos conceitos psicológicos, que estão na linguagem ordinária, seja subsumida na unidade de um superconceito - a consciência. (HEBECHE, 2002, p. 15).

1 É comum que se faça uma distinção para diferenciar as ideias apresentadas na sua primeira obra, Tractatus Logico-Philosophicus, das ideias apresentadas em sua segunda obra, Investigações Filosóficas. Sendo que nesta segunda, o próprio autor realiza críticas à primeira. 
O que o autor busca salientar é que, o grande problema que permite surgir equívocos quando tratamos dos conceitos psicológicos está na busca de explicações fora da linguagem, seus significados são clarificados no uso que fazemos destes dentro da própria linguagem, nos contextos, nas formas de vida, dentro do que o filósofo vem a chamar de "jogos de linguagem".

Isto é, no momento em que nos deparamos com dificuldades e confusões conceituais, podemos alcançar os esclarecimentos de forma terapêutica, seguindo um método de observação reflexiva, que ele veio a chamar de "terapia filosófica". O filósofo propõe uma "cura" para os equívocos que são oriundos do uso dogmático da concepção referencialista da linguagem, apontando a necessidade de termos uma visão panorâmica de seu significado, a fim de fugir desses equívocos. Em outras palavras, que olhemos para os diversos usos que uma palavra pode ter e suas conexões.

Uma fonte principal de nossa incompreensão é que não temos uma visão panorâmica do uso de nossas palavras. - Falta caráter panorâmico à nossa gramática. - A representação panorâmica permite a compreensão, que consiste justamente em "ver as conexões". (WITTGENSTEIN, 1975, §122).

Para tanto, devemos mudar nosso modo de conceber as coisas do mundo e reconhecer que há outras maneiras de vê-las, como por exemplo, a multiplicidade de aplicações atribuídas ao mesmo conceito ou palavra. É importante que queiramos ver de outro modo, sendo assim, devemos nos livrar dos dogmatismos e em relação ao nosso modo de ver habitual, para tal, seria necessária uma reflexão gramatical do uso das palavras nos jogos em que estão inseridas, deste modo poderíamos evitar tais confusões. Assim, o esclarecimento é dado no momento em que tal sentido é visto como algo convencionado e elaborado dentro do processo de uso de determinadas palavras que estão sob regras normativas de sentido (SILVEIRA; TEIXEIRA JÚNIOR; SILVA, 2018). 


\section{Tratamento terapêutico dos conceitos psicológicos: raciocínio lógico e memória}

Quando falamos de conceitos psicológicos, tais como raciocínio lógico, memória, vemos na literatura da Educação Matemática, que tais conceitos, em alguns casos (OLIVEIRA, 2010; GOBET \& JANSEN, 2007), estão sendo tratados como se fossem processos mentais ocorridos dentro de algum lugar oculto, algo físico, onde é armazenado todo o tipo de informação e que o aluno necessita realizar "pesquisas" para encontrá-la e isso ocorre como consequência do fato de ainda muitos conceitos estarem "presos" a uma concepção referencialista da linguagem, pois desta maneira procuramos um lugar, ou uma parte interna do corpo (mecanismos cerebrais), onde possamos apontar ou expressar ordinariamente para fazer referência ao significado de tais conceitos.

Cristiane Gottschalk (2004), em uma de suas pesquisas sobre a natureza do conhecimento matemático, evidenciou três perspectivas mais presentes na Educação matemática, a primeira seria a concepção realista da matemática, uma concepção empirista, onde as verdades matemáticas seriam obtidas através de generalizações da experiência. Outra perspectiva seria a cognitivista, que considera a construção dos objetos matemáticos decorrentes de operações mentais que se desenvolvem por interação com o meio. Por último, a perspectiva na qual apenas transpõem a posição mentalista cognitiva para o social. Isto quer dizer que para todas essas vertentes, o conhecimento da matemática, é adquirido por meios de "objetos" que preexistem, seja no empírico, no mental ou na intersubjetividade social. Diante disto, percebemos o quanto a concepção referencialista da linguagem está presente, não somente na maneira de ensinar, ou de "ver" a matemática, mas na maneira de compreender como é realizado o desenvolvimento de aprendizagem do aluno.

As assimetrias entre o 'interno' e o 'externo', legadas pelas tradições filosóficas cartesianas e empiristas, derivariam do mau uso da linguagem no que se refere às expressões mentalistas e suas articulações com o comportamento. (FARIA; RODRIGUES, 2011, p. 53). 
É essa tendência em buscarmos sempre algum referencial, algo fora da linguagem, alguma essência que nos direcione à explicação da palavra, ou do conceito, essa busca por um "superconceito" dos aspectos psicológicos, que nos induz a cair nos devaneios da confusão e dos equívocos conceituais da linguagem (HEBECHE, 2002). Gottschalk (2015) apresenta uma análise dos usos de conceitos educacionais, como o uso dado ao conceito de ensinar, e mostra o quanto ainda estamos inclinados ao referencialismo da linguagem:

O ensino é visto como uma atividade que envolve a transmissão de significados extralinguísticos, seja a perspectiva platônica da existência de um reino ideal a ser acessado através de um processo de rememoração, seja uma perspectiva mais pragmática como a de Dewey, em que predomina o critério da utilidade como legitimação de nossas verdades. Compelidas desta maneira, por uma concepção referencial da linguagem, as razões que as diversas teorias pedagógicas apresentam para justificar nossas crenças apoiam-se, na maior parte das vezes, em entidades metafísicas, significados últimos que transcenderiam o plano linguístico. (GOTTSCHALK, 2015, p. 310).

Como a autora ressalta, essas crenças compelidas pela concepção referencialista da linguagem são uns dos motivos que nos levam a cair em certos equívocos ao utilizarmos os jogos e objetos matemáticos no ambiente escolar, como apontado nas pesquisas acerca da utilização desses jogos, relacionadas ao desenvolvimento de habilidades que favorecem o aprendizado do aluno na matemática, e até mesmo no que diz respeito à outras áreas de conhecimentos. Porém, esses desenvolvimentos são analisado apenas como processos psicológicos, psicofísicos (FARIA; RODRIGUES, 2011), independente da linguagem. Diante disto, nossa busca é observar estes conceitos psicológicos de forma terapêutica, e clarificar a maneira como é vista a utilização dos jogos e dos objetos matemáticos como recurso pedagógico. Chauviré, de acordo com as ideias de Wittgenstein, nos diz que,

Os jogos são livres criações do espírito e da vontade, autônomos e governados por regras. Saber jogar um jogo é uma capacidade que supõe o domínio de uma técnica, consecutiva a uma aprendizagem. $\mathrm{O}$ fosso que separa a regra de sua aplicação é preenchido pelo treinamento ou adestramento, a familiaridade, a prática do jogo. (CHAUVIRÉ, 1989, p. 91).

Primeiro ponto que podemos extrair da fala da autora, é o fato de que saber jogar é uma capacidade, uma técnica. Ora, se é uma técnica ela pode ser ensinada, 
nesse caso, ela não decorre de um processo oculto, individual, autônomo, mas sim de um aprendizado, logo, de um conhecimento que passou por observações das regras descritas do jogo por parte de quem aprendeu. O segundo ponto é o treino, que tomaremos aqui como a prática, a ação de aplicação da regra, ou seja, o aprendizado depende de exercitar a aplicação, ou modo de usar determinada regra pertencente a um jogo.

Os jogos e objetos matemáticos, por serem em suas plenitudes definidos por regras, podem ser vistos como excelentes ferramentas de "exercitações" de regras. Dentre as habilidades atribuídas à prática dos jogos, podemos destacar duas habilidades essenciais para um bom aprendizado matemático, a memorização e o raciocínio lógico, este uns dos mais fundamentais para um bom desempenho no aprendizado da matemática. Saber raciocinar logicamente vai além das escolhas as quais devamos seguir, mas segue do domínio de compreensão de seus significados, que segundo a perspectiva Wittgensteiniana, são seus usos.

Wittgenstein (2008) fala sobre os conceitos psicológicos e dentre eles destaca o conceito de pensar, por exemplo quando dizemos "Estava pensando nas possibilidades de lance do bispo", no momento em que encontramos diante de uma partida de xadrez, ou quando dizemos "Preciso pensar um pouco mais a respeito disso", em casos nos quais precisamos tomar uma decisão, ou, ainda, quando dizemos "Estava pensando naquela partida de xadrez que executamos em nosso último encontro", ao lembrar dos lances, dos erros cometidos, etc., estamos dizendo a mesma coisa com a palavra "pensar"? O conceito de pensar é utilizado de diversas formas e em diversos contextos, sem que possua uma essência ou traço comum dentre eles.

Assim como o conceito de querer, o pensar não é um processo mental e seu caráter de sublime é desfeito, à medida que forem descritos seus usos na linguagem [...]. Trata-se então de compreender que o conceito de pensar participa de jogos-de-linguagens distintos, mas afins, e, destarte, não há um modo unilateral do pensar, mas semelhanças que constituem este "fenômeno". (HEBECHE, 2002, p. 117-120).

Para Giannotti, pensar é uma atividade reflexionante. Pois, como ele afirma: 
Pensar é manipular sinais, cabe atentar para os matizes de sentidos que são apresentados a este verbo. Essa manipulação implica cumprir a intenção do jogo, o que de certo modo o abre para melhorar seu desempenho. Sem precisar estar ligado à consciência de si, pensar consiste num ato voluntário que se abre para o mundo por meios de passos determinados. (GIANNOTTI, 1995, p. 212).

Assim, como podemos ver, o "pensar" não é um processo mental oculto do qual pouco sabemos. O significado de "pensar" é constituído pelos diversos usos dessa expressão em diversificados contextos de aplicação, nos quais podemos distinguir aspectos diferentes em sua aplicação (que podem se assemelhar a refletir, lembrar, lamentar, etc). Semelhante a isto, podemos tomar da mesma compreensão para o uso dos conceitos psicológicos utilizados no campo da Educação Matemática, principalmente no que diz respeito ao uso dos jogos no ambiente escolar: o raciocínio lógico, por exemplo, não é um "algo" em nossa mente, mas seu uso nos mostra seu significado. Ora, o raciocínio lógico não é um processo mental que deve ser "despertado" na mente do aluno, mas uma habilidade que é aprendida, e isto pode ser feito por meio de jogos que assim a requeiram aprender.

Porém, a terapia deveria pautar-se pelo respeito à naturalidade, ao caráter orgânico da linguagem e a espontaneidade de seu bom funcionamento: não se tratava de reformá-la, por artificial que pudesse parecer o desenraizamento forçado dos problemas filosóficos. Longe de procurar corrigir a linguagem em função de um modelo lógico procustiano, visava-se uma simples apresentação global de fatos já conhecidos por todos, mas agenciados de outra maneira, uma Ubersicht capaz de libertar o entendimento das imagens pregnantes que 0 obsedam: "Apaziguo assim essa espécie de caibra que lhe trava o espírito, e poderá examinar livremente o domínio do uso da expressão em descrever suas formas" - nota de Malcolm. (CHAUVIRÉ, 1989, p.130).

Desta maneira, por Wittgenstein, é que compreendemos que é necessário fazer uma terapia, onde possamos estar deixando de lado a visão equivocada que fazemos ao dizer que o significado é algo definido, referente a um "objeto", mas que o seu real significado está no uso que fazemos da linguagem, nos diversos meios, como Wittgenstein nos apresenta, nas diversas formas de vida, nos seus diferentes contextos, ou seja em meio aos jogos de linguagem. Segundo Hebeche (2002), para Wittgenstein, o conceito de pensar é seguir as regras de uso as quais as palavras estão inseridas em certos jogos de linguagem. E ainda, por meio dessa 
afirmação, que o significado está nos usos. Como podemos dizer que nosso aluno desenvolveu o raciocínio lógico, ou passou a raciocinar melhor? como afirma Donat,

É possivel identificar no comportamento de uma pessoa suas experiências subjetivas porque diferentes traços deste comportamento são conectados num esquema que se torna padrão característico daquela experiência; não um elemento único que permite identificar a experiencia em questão, mas estes diferetes traços que juntos, nos permitem ver os comportamentos numa totalidade expressiva da experiência subjetiva. Por isso, é somente dentro de um jogo de linguagem que acontece a identificação e a caracteriação das experiências subjetivas. (DONAT, 2015, p.202).

Quando passamos a observar a maneira como o conceito de raciocínio lógico é utilizado dentro da literatura da Educação Matemática, nos deparamos com algumas diferenças na forma como é expressada. Para Oliveira (2010), o raciocínio lógico é um processo cognitivo, e quem a desenvolve é capaz de saber agir corretamente diante de um problema específico, é o agir humano, no momento em que precisa solucionar um problema. Para Morbach (2017), baseada nas ideias de Piaget, o raciocínio lógico é uma ação mental, que possibilita a criança fazer deduções e levantar hipóteses e que pode ser verbalizada. Rodrigues Neto (2008) nos diz que raciocinar logicamente é saber chegar a solução de um problema. Moro (2009), fala que raciocínio logico matemático é a capacidade de executar corretamente atividades pois, é por meio da ação repetida diretamente com os problemas matemáticos que o aluno desenvolve tal habilidade. Para Sarmento (2010), o raciocínio lógico é a capacidade de fazer inferência entre diversos saberes, pois para ele o aluno alcança tal êxito no momento em que ele passa a relacionar a compreensão simbólica, com os conceitos que o aluno já possui, e com isso fazer a vinculação com cotidiano do aluno.

Como se vê, o conceito de raciocínio lógico, conforme utilizado em trabalhos da Educação Matemática, embora apresente semelhanças em seus diversos usos, expressam atitudes e capacidades diferentes para suas aplicações, o que não significa que um exclua o outro, mas que ambos são aceitos em suas próprias concepções. Ainda podemos acrescentar as seguintes frases: "não estou conseguindo raciocinar", quando na verdade queremos dizer que não conseguimos 
compreender algo que está sendo explicado; "você não raciocinou?!", quando nos referimos a um erro que alguém cometeu; e, "que raciocínio!", quando queremos expressar um sucesso em uma prova, ou seja, temos diversas aplicações do conceito de raciocínio, e estes usos, seus significados, se dão dentro de determinados jogos de linguagens, como dito por Wittgenstein $(1975, \S 7)$ : "é a totalidade formada pela linguagem e pelas atividades de usos com as quais elas vem entrelaçadas".

Tomando-se do mesmo procedimento, de analisarmos os diferentes usos dos conceitos, feito para o conceito de "Raciocínio Lógico", podemos esclarecer também os diversos significados dados aos conceitos das demais habilidades relacionadas ao uso de jogos, tais como a memória, a concentração, o desenvolvimento de estratégias, etc. Por conseguinte, podemos compreender que o conceito dessas habilidades, são constituídas por seu diversos usos afins, e não por um "superconceito" referente a um processo mental misterioso.

Partindo deste mesmo entendimento, nos apropriaremos da definição encontrada no dicionário Aurélio: memorizar seria nada mais que fixar metodicamente, pela repetição sistemática, alguma coisa na memória, ou seja, seria nada mais que decorar. A memória seria aqui a capacidade que o ser humano possui de compendiar fatos e informações, reter conhecimentos sobre o passado. Diante disto, percebemos que as noções de memória recaem a um "algo", a um sistema de armazenamento, levando-nos a ver a memória apenas como uma imagem mental. Além desta percepção, também observamos a utilização do conceito de memória quando nos referimos à área da informática, ao passo que dizemos, por exemplo, que meu computador possui $500 \mathrm{~Gb}$ de memória, quando me refiro à capacidade de armazenamento de dados do aparelho.

Como visto acima, a nossa intenção é, nos baseando nas ideias de Wittgenstein, promover uma análise terapêutica acerca de como o conceito de memória vem sendo tomado no campo educacional. Pelo que observamos, a ideia que emana nos leva a crer que a memória é como se fosse um sistema de armazenamento, semelhante a um tipo de caixinha onde tudo aquilo que foi 
vivenciado por alguém é depositado e que todas essas informações são os conteúdos da memória, a consequência desta utilização conceitual de memória é que nos leva a cair em grandes confusões e má compreensões.

A memória não é simplesmente um processo de representação de experiências, mas é todo o conjunto de nossas ações morais e de atitudes sobre as normativas de sociedade, por exemplo, é toda a nossa capacidade de lembrar os usos das palavras, das expressões corporais, dos jogos de linguagens que fazemos parte. Uma vez que essas expressões joguem conforme a regra do jogo que aparece em determinada forma de vida, meio social, contexto, etc.

Não se nega os processos físicos cognitivos, porém não se pode colocar a linguagem fora deles, o significados desses processos é o conjunto de usos que fazemos deles, ou seja, por Wittgenstein, "a constituição de sentidos não é imediata, mas sim intermediada por técnicas linguísticas" (GOTTSCHALK, 2015). Para tanto, "A experiência interna entra no jogo de linguagem via o comportamento e é pelo comportamento que aprendemos o significado da palavra, daquela experiência" (DONAT, 2015, p.201).

Para Wittgenstein (1975), os conceitos relativos ao interior estão intrinsecamente ligados ao comportamento no qual eles se expressam. Podemos, desta maneira, expandir tal entendimento para o uso dos conceitos de raciocínio lógico e memória, onde podemos, por analogia, dizer que o conceito de raciocínio lógico está diretamente ligado ao uso que fazemos dele, ou seja, neste caso, a maneira como agimos, as escolhas que tomamos de acordo com o pronunciamento da palavra, é o saber agir conforme a regra de uso estipulada para uma palavra dentro de um determinado jogo de linguagem, em outras palavras, são nossas ações diante das regras do uso do conceito, e não apenas atribuído aos funcionamentos físicos da estrutura mental. Sendo assim, como Gottschalk diz:

O que temos são simplesmente técnicas linguísticas que estabelecem relações de sentido, inventadas ao longo dos séculos e não descobertas. Desta perspectiva terapêutica, os "preconceitos", por exemplo, de que o aluno "descobre" relações matemáticas como o faz em suas experiências empíricas, ou de que haveria uma única racionalidade a ser desenvolvida no aluno (herança de Rousseau), ou ainda, de que o conhecimento possa ser extraído 
de uma realidade extralinguística, entre outros, são abandonados, abrindo-se espaços para um novo olhar para as questões do ensino e da aprendizagem, que passa a incorporar o papel da linguagem na constituição dos significados. (GOTTSCHALK, 2005, p.313).

De acordo com esta fala da autora, podemos entender que permanecer na busca incessante por uma explicação do que vem a ser o raciocínio lógico, do que vem a ser a memória, é na verdade a busca por um "pseudoproblema", decorrente apenas da falta de compreensão do funcionamento, usos, das palavras da nossa linguagem. Assim como aprendemos a andar, a sentar, a se vestir, aprendemos a agir, ou reagir diante de situações que necessitam de análises, reflexões, escolhas e consequências. Memorizar, raciocinar logicamente também são habilidades que podem ser aprendidas, e que por meio dos jogos, elas podem ser praticadas e nos proporcionar meios para alcançar assim o seu desenvolvimento.

Desse modo, como apontado na literatura (PENTEADO et al, 2011; OLIVEIRA; 2006, OLIVEIRA, 2010; CABRAL, 2006; KISHIMOTO, 2011; RODRIGUES NETO, 2008; SÁNCHEZ TORRES, 2010, SARMENTO, 2010), tais habilidades proporcionam um bom desempenho do aprendizado da matemática. À vista disso, as mesmas habilidades desenvolvidas em um são as mesmas para um bom desempenho na outra, logo, ao saber lidar com a manipulação das regras do xadrez, por exemplo, analogamente o aluno é capaz de manipular as regras na matemática, o que nos levar a pensar em habilidades mútuas. Com isso, podemos dizer que se faz necessário esclarecer alguns dos conceitos ligados aos processos que estão envolvidos na prática dos jogos, por meio da terapia wittgensteiniana dos conceitos psicológicos atribuídos a eles, para que assim, possa melhorar o planejamento de tais recursos pedagógicos para a sala de aula.

\section{Considerações}

Por meio da Terapia wittgensteiniana dos conceitos psicológicos podemos contribuir para a Educação Matemática. Pois desta maneira, os diversos recursos pedagógicos podem ser planejados, e utilizados de maneira mais eficaz, sendo analisado seu uso em meio à gramática presente no contexto de aplicação do jogo. 
Analisar os conceitos de maneira terapêutica acaba por vez evitando equívocos e confusões conceituais diante das variadas tendências educacionais, ou seja, entendermos que a linguagem não possui uma essência, não é referencialista a conteúdos, mas sua compreensão está no uso, ou seja, na sua linguagem, pois é ela quem dá significado aos seus mais diversos signos, é no seu uso, nos mais diversos contextos, ou seja, a compreensão partiria por meio da habilidade de dominar o jogo, que neste caso o jogo de linguagem ao qual está sendo inserido (SILVEIRA; TEIXEIRA JUNIOR; SILVA, 2018).

Portanto, para alcançarmos uma melhor compreensão a respeito das principais metodologias de ensino, necessitamos ter esse olhar terapêutico, analisar seus usos na linguagem, é necessário perceber que para se compreender a linguagem é preciso dominar certas habilidades, mais especificadamente, habilidades em dominar os jogos de linguagens, e como foi dito anteriormente, tais habilidades podem ser desenvolvidas por meio dos jogos e objetos matemáticos, daí parte a eficácia destes recursos pedagógicos. Como já foi visto, segundo Wittgenstein, compreender algo, é dominar uma técnica, e dominar uma técnica é saber dominar as regras. Sendo assim, é necessário extrair de nós mesmos a força dogmática que possuímos interiorizada em nós ao nos depararmos com as diferentes vertentes existentes no âmbito educacional e entendermos que todas as explicações dos mais diversos conceitos está presente na linguagem e não fora dela.

\section{Referências}

CABRAL, Marcos Aurélio. A utilização de jogos no ensino de matemática. Monografia - (Licenciatura em Matemática) - Universidade Federal de Santa Catarina, Florianópolis, 2006.

CHAUVIRÉ, Christiane. Wittgesntein. Tradução: Maria Luiza X. de A. Borges. Rio de Janeiro: Jorge Zahar Ed, 1989.

DONAT, Mirian. Os conceitos psicológicos considerados a partir do conceito de "ver um aspecto" de Wittgenstein. MORENO, Arley R. (org.). Wittgenstein e seus aspectos. Coleção CLE, v.72, 2015, p. 197-208. 
DONAT, Mirian. A noção Wittgensteiniana de consciência. DALL'AGNOL, Darlei; FATTURI, Arturo. SATTLER, Janyne. (org.). Wittgenstein em retrospectiva. Florianópolis: Editora da UFSC, 2012.

FARIA, Daniel Luporini; RODRIGUES, Cae. Linguagem, natureza humana e cognição: Wittgesntein e o problema mente-corpo. Ciência \& Cognição, v. 16, n. 1, p. 49-57, 2011.

FERREIRA, Regina França Guimarães; IGLIORI, Sonia Barbosa Camargo.

Competências cognitivas e aprendizagem de matemática. Ensino da Matemática em Debate, 2014, 1.2

GIANOTTI, José Arthur. Apresentação do mundo: considerações sobre o pensamento de Ludwig Wittgenstein. São Paulo: Companhia das Letras, 1995.

GOBET, Fernand; JANSEN, Peter J. Treinamento em xadrez: uma abordagem científica. FILGUTH, Rubens (Org). A importância do xadrez. Porto Alegre: Artmed, 2007.

GOTTSCHALK, A Natureza do Conhecimento Matemático sob a Perspectiva de Wittgenstein: algumas implicações educacionais. Cadernos de História e Filosofia da Ciência (UNICAMP), v. 14, 2004, p. 305-334.

GOTTSCHALK, Cristiane Maria Cornelia. A terapia wittgensteiniana como esclarecedora de conceitos fundamentais do campo educacional. Revista Latinoamericana de Filosofía de la Educación, 2015, 2.4: 299-315.

HEBECHE, Luiz. O mundo da consciência: ensaio a partir da filosofia da psicologia de L. Wittgenstein. Porto Alegre: EDIPUCRS, 2002.

KISHIMOTO, Tizuko Morchida. O jogo e a educação infantil. In: KISHIMOTO, Tizuko Morchida (Org.). Jogo, brinquedo, brincadeira e a educação. 14a ed. São Paulo: Cortez, 2011. p. 15-48.

MATTOS, Robson Aldrin Lima; FAGUNDES, Tereza Cristina Pereira Carvalho. A importância dos jogos para a construção de conceitos matemáticos. In: TENÓRIO, RM.; SILVA, RS (org). Capacitação docente e responsabilidade social: aportes pluridisciplinares. Salvador: EDUFBA, 2010, pp.77-96

MORBACH, Raquel Passos Chaves. O meta-jogo como instrumento à aprendizagem da matemática. In: Educação Matemática na Amazônia. Belém: SBEM/SBEM-PA, 2017.

MORO, Maria Lúcia Faria. Construtivismo e educação matemática. Educação Matemática Pesquisa: Revista do Programa de Estudos Pós-Graduados em Educação Matemática, v. 11, n. 1, 2009.

OLIVEIRA, Cléber Alexandre Soares de. O xadrez como ferramenta pedagógica complementar na educação matemática. Trabalho de Conclusão de Curso (Graduação) - Universidade Católica de Brasília, Brasília-DF, 2006. 
OLIVEIRA, Vera Barros de. Jogos de regras e a resolução de problemas. 4.ed. Petrópolis, RJ: Vozes, 2010.

PENTEADO, Lucas; COQUEIRO, V. S.; HERMANN, Wellington. O ensino de conteúdos matemáticos a partir do jogo de xadrez no Ensino Fundamental. [Anais do] VI Encontro de Produção Científica e Tecnológica - EPCT. Campo Mourão - PR, 2011.

RODRIGUES NETO, Antonio. Geometria e estética: experiências com o jogo de xadrez. São Paulo: Editora da UNESP, 2008.

SÁNCHEZ TORRES, Juan Diego. Jogos de matemática e de raciocínio lógico. Tradução de Guilherme Summa. 2ª ed. - Petrópolis, RJ: Vozes, 2013.

SARMENTO, Alan Kardec Carvalho. A utilização dos materiais manipulativos nas aulas de matemática. ufpi. br/subsiteFiles/ppged/arquivos/files/VI. encontro, 2010.

SILVA, João Esteves da. Cinco Ensaios sobre Wittgenstein. Lisboa, Portugal: Centro de Filosofia das Ciências da Universidade de Lisboa (CFCUL), 2010.

SILVA, Ana Maria Ferreira; DOS SANTOS, Vânia Machado; GOULART, Ilsa do Carmo Vieira. Os jogos como instrumentos de aprendizagem naalfabetização matemática. Cadernos da Pedagogia, São Carlos, Ano 11 v. 11 n. 22 jan-jun 2018.

SILVA, Paulo Vilhena; SILVEIRA, Marisa Rosâni Abreu. Matemáticas ou diferentes usos da matemática? Reflexões a partir da filosofia de Wittgenstein. Acta Scientiarum Education, Maringá, v. 35, n. 1, p. 125-132, jan./jun. 2013.

SILVEIRA, Marisa Rosâni Abreu; TEIXEIRA JÚNIOR, Valdomiro Pinheiro; SILVA, Paulo Vilhena. A terapia filosófica wittgensteiniana: perspectivas para a Educação Matemática. Revista de Educação, Ciência e Cultura, Canoas, v. 23, n. 1, p. 161-17, mar. 2018.

WITTGENSTEIN, Ludwig. Tractatus logico-philosophicus. Tradução de José Arthur Giannotti. São Paulo, Editora Nacional, 1968.

WITTGENSTEIN, Ludwig. Investigações Filosóficas. Tradução de José Carlos Bruni. São Paulo: Abril Cultural, 1975. (Coleção os pensadores).

WITTGESNTEIN, Ludwig. Observações sobre a filosofia da psicologia - vol. I e II. Tradução de Ricardo Hermann Ploch Machado. Aparecida, SP: Ideias \& Letras, 2008. (Subjetividade Contemporânea). 